\title{
The Periodic Table and Kinetics?
}

\author{
Lothar Helm* and André E. Merbach
}

\begin{abstract}
Mendeleev in his first publication ordered the chemical elements following an apparent periodicity of properties such as atomic volume and valence. The reactivity of the elements was only studied systematically many years later. To illustrate the systematic variation of kinetics across the periodic table we compare water residence times for monoatomic ions in aqueous solution. A tremendous variation of $\tau_{\mathrm{H}_{2} \mathrm{O}}$ by over 20 orders of magnitude is found, ranging from $\sim 10$ ps to about 200 years. Apart from some small +2 and +3 cations, all main group elements have very short residence times $<10 \mathrm{~ns}$. Transition metal cations of the d-block have water residence times that depend on the electronic configuration. $\tau_{\mathrm{H}_{2} \mathrm{O}}$ of lanthanide ions are surprisingly short with values of $10 \mathrm{~ns}$ and shorter. This is due to an equilibrium between 8 and 9 coordinated ions leading to a low energy of the transition state for the water exchange reaction.
\end{abstract}

Keywords: Ions in solution · Periodic Table $\cdot$ Water exchange

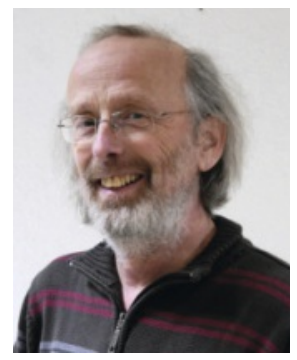

Lothar Helm studied physics at the Technical University of Karlsruhe (Germany) where he obtained his $\mathrm{PhD}$ in physical chemistry with Prof. H. G. Hertz. In 1980 he came to the University of Lausanne to work as a PostDoc with Prof. A. E. Merbach. Three years later he was appointed 'Agrégé de la Faculté' at the Institute of Inorganic and Analytical Chemistry at the University of Lausanne. In the group of André Merbach he participated in the development of high-pressure NMR equipment which was used to elucidate reaction mechanisms in inorganic chemistry. In 2001 the chemistry department of the University of Lausanne was merged with chemistry at Ecole Polytechnique Fédérale Lausanne (EPFL). After 5 years as 'Maître d'Enseignement et de Recherche' (MER) Lothar Helm was appointed adjunct professor at EPFL. In the last years of his career, Lothar Helm conducted physico-chemical studies of gadolinium-based MRI contrast agents. After his retirement in 2018 he became Honorary Professor at EPFL.

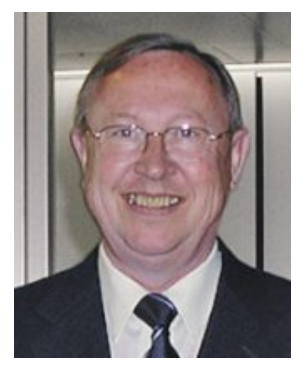

André E. Merbach was born in Lausanne in 1940. He studied at the Polytechnic School of the University of Lausanne, where he obtained in 1962 his degree in Chemical Engineering. He then completed his chemical education in the Institute of Inorganic and Analytical Chemistry of the University of Lausanne where he received his $\mathrm{PhD}$ in 1964. He held a Postdoctoral Fellowship at the University of California Berkeley. Upon his return in 1965 at the UNIL, he was asked to create a research and teaching program in Coordination Chemistry. $\mathrm{He}$ was appointed Professor in 1971 and in 1973 the Swiss Chemical Society awarded him the Werner Prize. He was member of the National Council of the Swiss NSF, academic representative at the Committee of the Swiss Chemical Industries Society, President of the Swiss Chemical Society, chaired the chemistry program within the COST European Program and was awarded doctor-

\footnotetext{
${ }^{*}$ Correspondence: Prof. L. Helm

E-mail: lothar.helm@epfl.ch

Institute of Chemical Sciences and Engineering ISIC, EPFL, Station 6,

$\mathrm{CH}-1015$ Lausanne
}

ates honoris causa from the Kossuth University of Debrecen in 1990 and from the University of Geneva in 2003. The focus of his research is on ligand exchange rates and mechanisms on metal complexes using a global analysis involving temperature and high-pressure technologies. These techniques were also applied to study contrast agents in medical magnetic resonance. Since 2005, André Merbach is Honorary Professor at the EPFL.

\section{Introduction}

In his publication of 1869 Mendeleev ordered the chemical elements in a table with increasing atomic masses in vertical columns in such a way that horizontal rows contain analogous elements again with increasing atomic mass (Fig. 1). ${ }^{[1,2]}$ He found an apparent periodicity which allowed foreseeing characteristic properties on the basis of the atomic mass. Amongst the properties were atomic volume and valency, which he found to recur periodically after seven elements. ${ }^{[3]}$ The reactivity of the elements could not be considered in this early work because of the then lack of experimental data. Modern research on chemical reactions started in 1864 with the formulation of the law of mass action by Guldberg and Waage. ${ }^{[4]}$ Only twenty years later van't Hoff published his 'Studies in Chemical Dynamics' which won him the first Nobel prize in chemistry in 1901.[5]

What about the reactivity of chemical elements? Is there also a periodicity as seen for valency? This question is difficult to answer in a general way. The first difficulty consists in the simple fact that most elements in their elemental form are present as solids at ambient temperature and only a few as mono- or diatomic gases (bromine and mercury are the only elements to be liquids at room temperature). The second difficulty is in the nature of a potential reaction partner. Reactivity of metal ions with, for example, a halogen like $\mathrm{F}_{2}$ or $\mathrm{Cl}_{2}$ varies differently across the periodic table compared with the reactivity with hydrogen $\mathrm{H}_{2}$ or oxygen $\mathrm{O}_{2}$. Furthermore, reactions in solution can strongly depend on the solvent used and are different from reactions on the surface of solids or in the gas-phase.

In this short review, we have chosen to compare reactivity of monoatomic ions in aqueous solution. The reason is simply that metals, which represent $\sim 80 \%$ of the chemical elements, form monoatomic cations with charges varying from +1 to +4 . For most of them salts can be found which are soluble in water. Water molecules have an electric dipole moment with a negative charge on the oxygen atom and positive charges on the two hydrogen atoms. In solution, cations are therefore solvated by water mol- 


\section{ОПЫТЬ СИСТЕМЫ ЭЛЕМЕНТОВЬ,}

ОСНОВАННОЙ НА ИХЪ АТОМНОМЪ ВЪСЬ И ХИМИЧЕСКОМЪ СХОДСТВЪ.

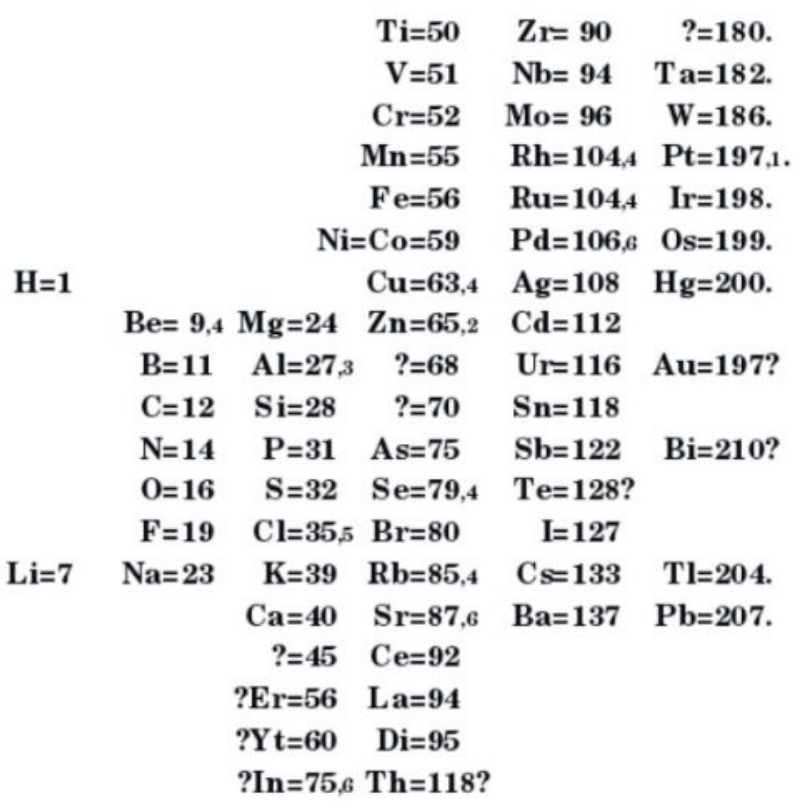

Д. Мендельевъ

Fig. 1. Periodic table of chemical elements as published by Mendeleev in J. Russ. Chem. Soc. in 1869.

ecules with oxygen adjacent to the metal ion (Fig. 2, left). This hydrated complex formed by the cation and the direct neighbours of $\mathrm{H}_{2} \mathrm{O}$ molecules, the first hydration shell, is not a static unit water molecules are exchanged either with other water molecules from the liquid leading to a water exchange reaction or with other dissolved molecules leading to complex formation. Both reactions, water exchange and complex formation, are closely related as has been shown more than 60 years ago.[6,7] The rate constant for water exchange, $k_{\mathrm{H}_{2} \mathrm{O}}$, or linked to it the mean residence time of a water molecule in a hydrate complex, $\tau_{\mathrm{H}_{2} \mathrm{O}}$, vary tremendously for different metal ions, as we will see later.

From the nonmetal chemical elements only halogens (group 17, Fig. 3) form monoatomic ions in solution, which are anions

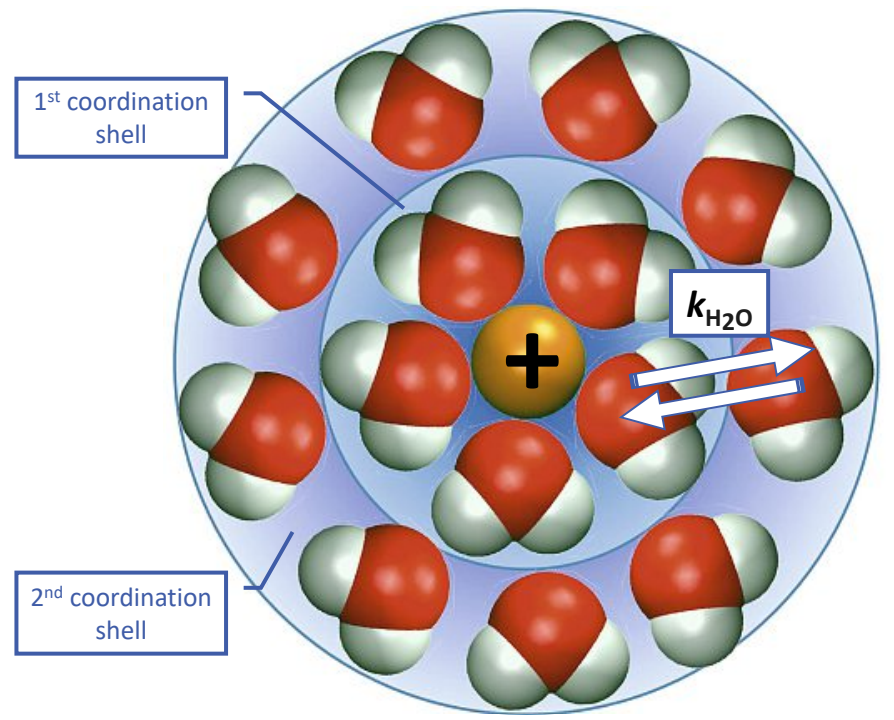

with a -1 charge (hydride $\mathrm{H}^{-}$and sulphide ions $\mathrm{S}^{2-}$ both react with water). The halide anions $\mathrm{X}^{-}(\mathrm{X}: \mathrm{F}, \mathrm{Cl}, \mathrm{Br}, \mathrm{I})$ are also hydrated in water, but in this case, a hydrogen atom of $\mathrm{H}_{2} \mathrm{O}$ is adjacent to the ion (Fig. 2, right). Again, water molecules have a characteristic residence time in these aqua anions.

In this paper, we will use the residence time of water molecules in the first coordination shell of ions to classify reactivity and kinetics of elements in the periodic table.

\section{Water Residence Time and how to Determine it}

\subsection{Hydration of Ions}

Before discussing the variation of water residence times over the periodic table we will show how water molecules solvate cations and anions in solution (Fig. 2). Around a cation (Fig. 2, left) we can distinguish one, two or, in rare cases, three shells of water molecules. These water molecules are different from 'normal' water molecules in bulk water mainly due to their dynamical behaviour: their rotational and translational diffusion is in general slower than that of bulk water. This slower dynamics is observed specially for water in direct contact with the cation, forming the first coordination shell. The number of water molecules in the first coordination shell, the coordination number, varies from 4 for $\mathrm{Be}^{2+}$ to 9 for the early lanthanide ions like $\mathrm{La}^{3+}$ or $\mathrm{Nd}^{3+}$. Most cations are surrounded by six water molecules forming an octahedron. In all cases, the negatively charged oxygen atom of the water molecules points towards the cation.

Around an anion, the specific organization of water molecules is less pronounced. ${ }^{[8]}$ In the first coordination shell water molecules are oriented with one of the positively charged hydrogen atoms pointing toward the anion (Fig. 2, right). The first shell coordination number increases from 6 to 8 from the small $\mathrm{F}^{-}$to the large $\mathrm{I}^{-}$anion.

The ion and its first coordination shell do not form a static entity. The water molecules are wagging, librating and from time to time even leaving the first coordination shell. If a water molecule leaves the $1^{\text {st }}$ shell it is in general immediately replaced by another water molecule entering from the $2^{\text {nd }}$ coordination shell. This 'exchange reaction' is called a dissociative exchange reaction, $\mathbf{D}$, because dissociation is the first step in the reaction pathway. ${ }^{[9]}$ If the first step is the entry of a $2^{\text {nd }}$ shell water molecule into the $1^{\text {st }}$ shell followed by the exit of another one, the reaction is called an associative exchange reaction, A. Both processes can happen more or less simultaneously; in this case an interchange exchange mech-



Fig. 2. Schematic drawing of the coordination shells of a cation (left) and an anion (right) showing water exchange of a single water molecule with a rate constant $k_{\mathrm{H}_{2} \mathrm{O}}$. 

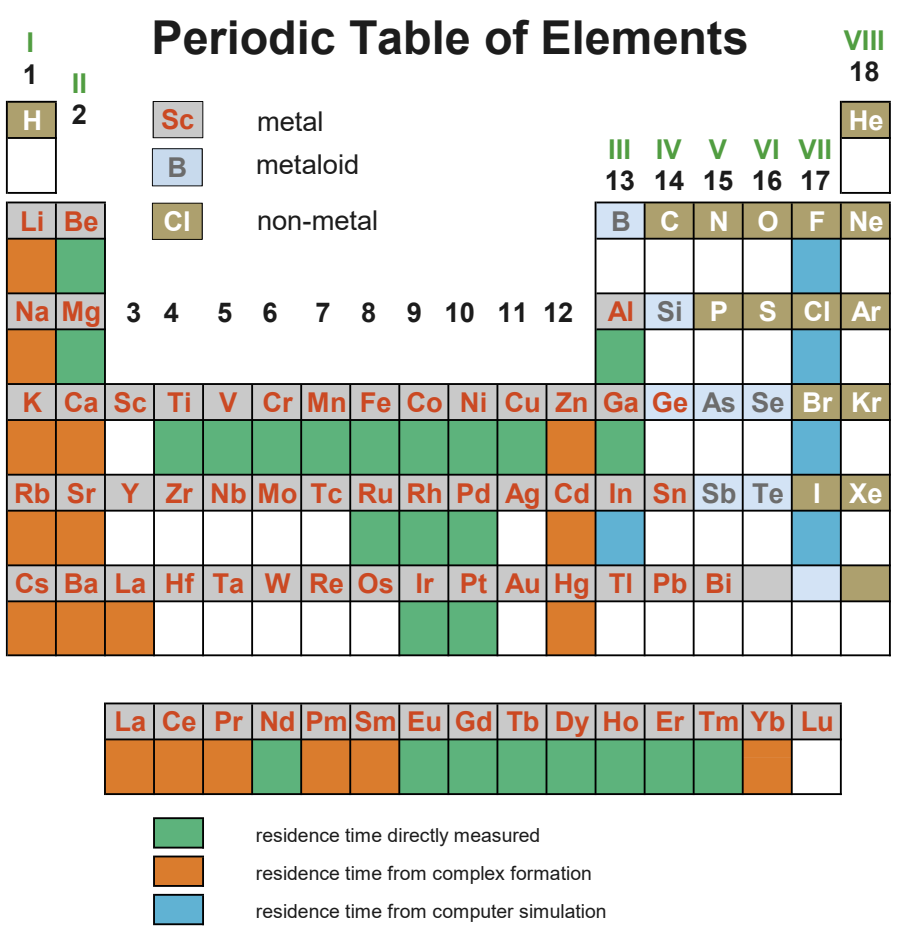

Fig. 3. Availability of water residence times $\tau_{\mathrm{H}_{2} \mathrm{O}}$ on monoatomic ions.

anism, $\mathbf{I}$, is active which can have a more or less dissociative $\left(\mathbf{I}_{d}\right)$ or associative character $\left(\mathbf{I}_{\mathbf{a}}\right)$. In any case, the exchange reaction can be characterized by a rate constant $k_{\mathrm{H}_{2} \mathrm{O}}$ which counts how many times a particular $1^{\text {st }}$ shell water molecule exchanges per second. The residence time $\tau_{\mathrm{H}_{2} \mathrm{O}}$ of a coordinated $\mathrm{H}_{2} \mathrm{O}$ molecule is then simply related to the inverse of the rate constant, $\tau_{\mathrm{H}_{2} \mathrm{O}}=k_{\mathrm{H}_{2} \mathrm{O}}^{-1}$. Because there are several water molecules in the first shell and all of them can exchange independently the total number of exchange events is $n k_{\mathrm{H}_{2} \mathrm{O}}$ with $n$ being the first shell coordination number. In the literature the rate constant of one specific water molecule, named $k_{\mathrm{H}_{2} \mathrm{O}}$ or $k_{\mathrm{ex}}$, is generally given, because this is the constant normally determined experimentally and it is independent of the coordination number.

\subsection{Determination of Residence Times}

Residence times of solvent molecules cannot be measured easily: in exchange reactions, there is no change in concentrations to be observed as in normal chemical reactions. There are only two experimental techniques which allow $k_{\mathrm{H}_{2} \mathrm{O}}$ to be measured directly: the first one relies on the use of isotopes and the second is based on nuclear magnetic resonance (NMR). The isotope technique is founded on the chemical equivalence of isotopes. Water isotopically enriched in the stable ${ }^{18} \mathrm{O}$ isotope has been used to study very slow water exchange reactions. ${ }^{[10,11]}$ The isotope exchange technique is, however, limited to slow reactions with residence times longer than seconds. ${ }^{[12]}$

NMR-based techniques are by far the most used to study water exchange reactions. In general, ${ }^{17} \mathrm{O}$ NMR is used to avoid ambiguities due to proton exchange, which can be faster than the exchange of the whole water molecule. Different NMR techniques can be applied like isotopic labelling with $\mathrm{H}_{2}^{17} \mathrm{O}$, analysis of the NMR lineshape and measurement of $T_{1}$ and $T_{2}$ relaxation rates. ${ }^{[13]}$ Depending on the dia- or paramagnetic character of the metal ion, residence times from nanoseconds up to days and weeks can be measured directly.

Limits on the ion to water-proton binding time, which is in the case of fast exchange equal to the residence time of whole water molecules, can be obtained from incoherent quasi-elastic neutron scattering (IQENS). ${ }^{[14]}$ The method allows hydrated ions to be classified into those with residence times $\tau \leq 10^{-10} \mathrm{~s}$, with $\tau>10^{-10} \mathrm{~s}$ and with $\tau \geq 5 \cdot 10^{-9} \mathrm{~s}$ (Table 1 ).
Table 1. lon-water proton binding times, $\tau$, from incoherent quasi-elastic neutron scattering experiments ${ }^{[14]}$

\begin{tabular}{c|c|c|}
\hline \multicolumn{1}{c}{$\mathbf{1 0}^{-\mathbf{1 0}}[\mathbf{s}]$} & $\tau>\mathbf{1 0}^{-\mathbf{1 0}}[\mathbf{s}]$ & $\tau \geq \mathbf{5} \cdot \mathbf{1 0}^{-\mathbf{9}}[\mathbf{s}]$ \\
\hline $\mathrm{Li}^{+}$ & $\mathrm{Zn}^{2+}$ & $\mathrm{Mg}^{2+}$ \\
\hline $\mathrm{Cs}^{+}$ & $\mathrm{Al}^{3+}$ & $\mathrm{Ni}^{2+}$ \\
\hline $\mathrm{Ca}^{2+}$ & $\mathrm{Fe}^{3+}$ & $\mathrm{Cr}^{3+}$ \\
\hline $\mathrm{Cu}^{2+}$ & $\mathrm{Ga}^{3+}$ & \\
\hline $\mathrm{F}^{-}$ & $\mathrm{Nd}^{3+}$ & \\
\hline $\mathrm{Cl}^{-}$ & $\mathrm{Dy}^{3+}$ & \\
\hline $\mathrm{I}^{-}$ & & \\
\hline
\end{tabular}

Water residence times can be obtained in a more indirect way from complex formation rate constants. Eigen and co-workers have shown that very fast complex formation rate constants can be measured in water by ultrasonic absorption. ${ }^{[7,15]}$ The rate-determining step is the substitution of a water molecule by the ligand entering from the second coordination shell. For example, it has been found that this substitution rate constant for complex formation of lanthanide ions by sulphate $\mathrm{SO}_{4}^{2-}$ is close to that of water exchange rate constants measured directly by NMR.[16,17] It can therefore be used in cases where no directly measured rate constants are available.

A final possibility to gain insight into water exchange reactions on ions uses computer simulations. A variety of classical and quantum mechanical methods have been developed allowing information residence times to be obtained, amongst other things. ${ }^{[18,19]}$ The results obtained depend strongly on the simulation method chosen as well as the way by which residence times are extracted. In this short review, we will use simulation residence times for elements where no experimental data are available.

\section{Water Residence Time and the Periodic Table}

Water residence times in the first coordination shell of monoatomic ions vary over more than 20 orders of magnitude from ps to years (Fig. 4). This tremendous range reflects the varying interaction strength between the water molecule and the cation or the anion respectively.

\subsection{Main Group Elements}

The main group chemical elements belong to the $s$ and $p$ blocks of the periodic table. Hydrated monoatomic ions in solutions are known for the groups 1 (alkali), 2 (alkaline earth), 13 and 17 (halides).

\subsubsection{Alkali and Alkaline Earth Cations (s Block)}

Alkali and alkaline earth metals are present in aqueous solution as +1 and +2 charged cations, respectively. They have filled electron shells with a noble gas configuration. The interaction with water is mostly electrostatic and depends therefore on the charge and the ionic radius of the ion. The ion hydration of both groups is characterized by increasing coordination numbers with increasing ionic radii. $[20,21]$

The water residence times on alkali metal ions estimated from complex formation are below $10^{-8} \mathrm{~s}$ and decrease continuously from $\mathrm{Li}^{+}$to $\mathrm{Cs}^{+} .{ }^{[7,15]}$ The results from computer simulations show the same trend but calculated residence times are in general much shorter, being in the picosecond range. ${ }^{[18]}$ More sophisticated calculations performed on $\mathrm{Li}^{+}$led to residence times $\tau_{\mathrm{H}_{2} \mathrm{O}} \sim 100 \mathrm{ps},{ }^{[19,22]}$ which are closer to values estimated from complex formation.

Water residence times on the +2 alkaline earth ions are longer than on the alkali ions. For the first two members of the group, $\left[\mathrm{Be}\left(\mathrm{H}_{2} \mathrm{O}\right)_{4}\right]^{2+}$ and $\left[\mathrm{Mg}\left(\mathrm{H}_{2} \mathrm{O}\right)_{6}\right]^{2+}$ residence times have been meas- 


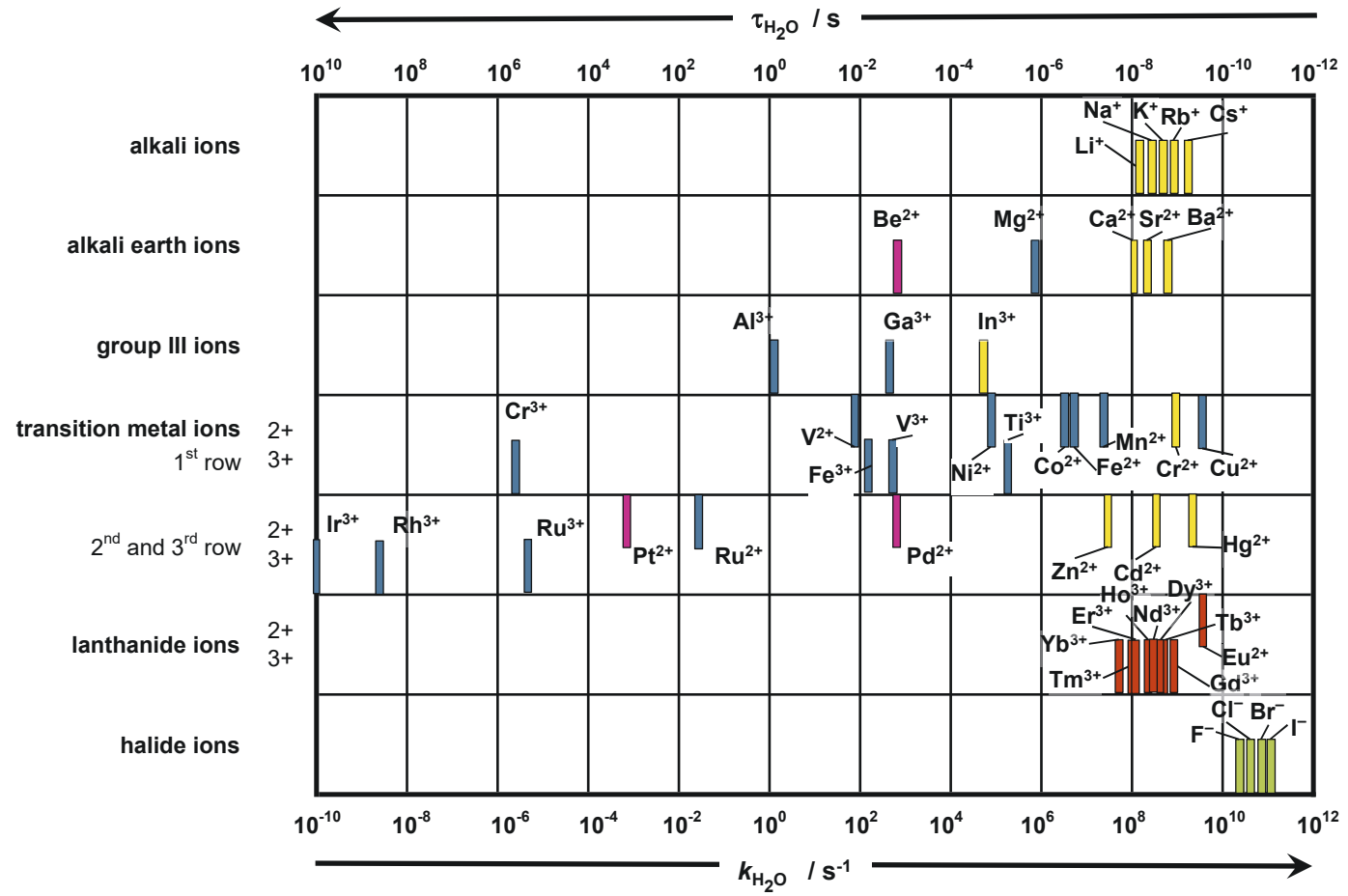

Fig. 4. Residence times and exchange rate constants $k_{\mathrm{H}_{2} \mathrm{O}}$ for monoatomic cations and anions in aqueous solution: blue: from direct measurements (6-coordinated); magenta: from direct measurements (4-coordinated): yellow: from complex formation; ${ }^{[15]}$ green: from computer simulations ured directly by NMR to be in the millisecond and microsecond time regime, respectively. ${ }^{[23,24]}$ These long residence times are due to the high positive electric charge density at the surface of the two small ions $\left(\mathrm{Be}^{2+}: r_{\text {ion }}=0.27 \AA, \mathrm{Mg}^{2+}: r_{\text {ion }}=0.72 \AA\right)$. ${ }^{[25]}$ The other ions of group 2, $\mathrm{Ca}^{2+}, \mathrm{Sr}^{2+}$ and $\mathrm{Ba}^{2+}$, have much faster water exchange as estimated from complex formation. ${ }^{[15]}$

\subsubsection{Group 13 Cations}

The elements of group 13, except boron, exist as +3 charged ions in water. The determination of water residence times on these ions is complicated by their tendency to hydrolysis. Residence times measured on $\mathrm{Al}^{3+}$ and $\mathrm{Ga}^{3+}$ show that $\tau_{\mathrm{H}_{2} \mathrm{O}}$ on hydrolysed aqua ions are orders of magnitude shorter than on homoleptic aqua ions. ${ }^{[26]}$ Again, the residence time decreases strongly from the top to the bottom of the group. Water residence times on $\left[\mathrm{Al}\left(\mathrm{H}_{2} \mathrm{O}\right)_{6}\right]^{3+[12]}$ and $\left[\mathrm{Ga}\left(\mathrm{H}_{2} \mathrm{O}\right)_{6}\right]^{3+[27]}$ have been measured directly by NMR in highly acidic solutions. The residence time on $\left[\mathrm{Al}\left(\mathrm{H}_{2} \mathrm{O}\right)_{6}\right]^{3+}$ is about $1 \mathrm{~s}$ which is the longest measured on main group ions in water.

\subsubsection{Halide Anions (Group 17)}

The interaction between halide anions $\mathrm{X}^{-}(\mathrm{X}: \mathrm{F}, \mathrm{Cl}, \mathrm{Br}, \mathrm{I})$ and water is very weak as shown by neutron diffraction studies ${ }^{[28]}$ and computer simulations. ${ }^{[29,30]}$ The results from incoherent quasi-elastic neutron scattering (IQENS) give only upper limits for water residence times with $\tau>10^{-10} \mathrm{~s}$. The data from computer simulations strongly depend on the method chosen as well as the parameters used in the simulation. Recent results give $\tau_{\mathrm{H}_{2} \mathrm{O}}$ $\sim 10^{-11} \mathrm{~s}$ with no clear trend on going from $\mathrm{Cl}^{-}$to $\mathrm{I}^{-}{ }^{[30]}$ Water molecules are bound with one of the protons pointing towards the anions (Fig. 2, left) and the interaction between the solvent molecule and the ion is purely electrostatic. The interaction between the halide anions and water is much weaker than between alkali cations and water, which is mainly due to the lower point charge on $\mathrm{H}$ compared to that on $\mathrm{O}$; the $\mathrm{Cl}-\mathrm{D}$ distance as measured from neutron diffraction is $2.26 \AA$ compared to $2.32 \AA$ for $\mathrm{Na}-\mathrm{O} .{ }^{[28,31,32]}$

\subsection{Transition Metal Cations}

In this review, we consider as transition metal ions cations of elements belonging to the d-block and f-block. We restrict ourselves to non-radioactive elements excluding, for example, actinides.

\subsection{1 d-Block Elements}

Elements of the d-block of the periodic table are chemical elements of groups 3 to 12 . Many of them form +2 and/or +3 ions which are redox stable in aqueous solution. Ions of group $3\left(\mathrm{Sc}^{3+}\right.$, $\mathrm{Y}^{3+}$ and $\mathrm{La}^{3+}$ ) have properties similar to lanthanide ions and form together the rare earth elements. No experimental data is available on these three fast exchanging diamagnetic ions.

Water exchange on the paramagnetic first row transition metals has been studied extensively using NMR techniques. All ions except the pentacoordinated $\mathrm{Cu}^{2+[33,34]}$ have six water molecules in the first coordination shell. The mechanism for water exchange depends on the filling of the $3 \mathrm{~d}$ orbitals and changes from associative to dissociative along the period. ${ }^{[26]}$ The water residence time is mostly determined by the influence of the crystal field stabilization energy on the ground state and on the transition state of the aqua complex. ${ }^{[35]}$ If this stabilization is high, as for example for $\mathrm{Cr}^{3+}$, the water residence times are very long. A nice illustration of this influence is the $\mathrm{V}^{2+} / \mathrm{V}^{3+}$ couple of ions. Normally water residence times are longer on +3 charged ions compared to +2 charged ones. This is due to the stronger interaction with higher charge and shorter distance (smaller ionic radius for +3 ions compared to +2 ions of the same element). In the case of vanadium, this order is reversed by crystal field effects: the residence time on $\mathrm{V}^{2+}(11 \mathrm{~ms})$ is about 6 times longer than on $\mathrm{V}^{3+}$. The mechanism of the water exchange reaction has no direct influence on the residence time. Water residence times on $\mathrm{Fe}^{2+}$ and $\mathrm{Mn}^{2+}$ are both relatively short, but the mechanisms are $\mathrm{I}_{d}$ (dissociative interchange) and $I_{a}$ (associative interchange), respectively. ${ }^{[26]}$ A special case is the hydration of $\mathrm{Cu}^{2+}$. In solid state, the copper ion is hydrated by six water molecules showing a Jahn-Teller distortion (elongation of two axial $\mathrm{Cu}-\mathrm{O}$ bonds). There is evidence that $\mathrm{Cu}^{2+}$ in aqueous solution is coordinated by five water molecules. ${ }^{[33]}$ In any case, water exchange is very fast and $\tau_{\mathrm{H}_{2} \mathrm{O}}$ is in the order of nanoseconds. ${ }^{[36]}$

There are few experimental water residence times for second and third row transition metals (Fig. 3). For the six-coordinated ions only $\mathrm{Ru}, \mathrm{Ir}$ and $\mathrm{Rh}$ have been studied. Residence times are much longer than on first row transition metal ions. Residence times on second row $\mathrm{Ru}^{2+/ 3+}$ are about 8 orders of magnitude longer than on first row $\mathrm{Fe}^{2+/ 3+} \cdot{ }^{[37]}$ Because of stronger crystal fields and weaker spin pairing energy, the ruthenium aqua-ions are both low- 
spin, which is in contrast to the iron aqua-ions, which are both high-spin. Consequently, crystal field stabilization energy (CFSE) is much larger for the octahedral aqua ions of ruthenium than for iron. The residence times on the group 9 ions $\mathrm{Rh}^{3+}$ and $\mathrm{Ir}^{3+}$ are the longest measured: 15 and 300 years at ambient temperature respectively. This shows that the interaction between metal ions and water oxygen can be very strong, stronger than for covalent bonds such as the $\mathrm{C}-\mathrm{O}$ bond in carboxylic acids: depending on $\mathrm{pH}$, the oxygen residence time on acetic acid is about 1 day. ${ }^{[38]}$ Another interesting comparison can be made for the isoelectronic $\mathrm{Ru}^{2+}$ and $\mathrm{Rh}^{3+}$ ions: water exchange for the divalent ruthenium ion is 7 orders of magnitude faster than on the trivalent rhodium ion. [39]

The four-coordinated square-planar complexes of $\mathrm{Pd}^{2+}$ and $\mathrm{Pt}^{2+}$ constitute a special case. Water exchange on $\left[\mathrm{Pd}\left(\mathrm{H}_{2} \mathrm{O}\right)_{4}\right]^{2+}$ is faster than on the 6-coordinated $\mathrm{Ru}^{2+}$ which is due o the existence of a low energy associative pathway. Descending the group from $\mathrm{Pd}$ to $\mathrm{Pt}$ again leads to an increase in $\tau_{\mathrm{H}_{2} \mathrm{O}}$ by about 6 orders of magnitude.

Water exchange on the group 12 ions $\mathrm{Zn}^{2+}, \mathrm{Cd}^{2+}$ and $\mathrm{Hg}^{2+}$ is fast and could not be directly measured so far. In contrast to the transition metal ions of groups 4 to 11 , these ions have filled d-orbitals. The electrons of the Lewis base $\mathrm{H}_{2} \mathrm{O}$ cannot interact with empty d-orbitals and the interaction is therefore mainly electrostatic. The decrease of interaction from $\mathrm{Zn}^{2+}$ to $\mathrm{Hg}^{2+}$ is due to the increase of the ionic radius going down the group 12. [25]

\subsection{2 f-Block Elements}

The only non-radioactive f-elements are lanthanides (with exception of promethium, which is radioactive). These 14 elements are members of the group 3 and characterized by the filling of the $4 \mathrm{f}$-orbitals. The f orbitals are inner orbitals and the small influence of the crystal field results in the lanthanides being very similar chemically. The main differences come from the decreasing ionic radius along the series, called the lanthanide contraction. All lanthanides have stable +3 ions in aqueous solution. The coordination number is nine for the light lanthanides and eight for the heavy ones, ${ }^{[26,40]}$ with a changeover in the middle of the series around $\mathrm{Sm}^{3+}$. This change in coordination number is responsible for the peculiar variation of the water residence time: the exchange rate constant increases from the beginning of the series to a maximum around $\mathrm{Sm}$ or $\mathrm{Gd}$, and decreases then until the end of the series (Fig. 5). ${ }^{[26]}$ This behaviour is shown by the directly measured rate constants $k_{\mathrm{H}_{2} \mathrm{O}}{ }^{[17,41,42]}$ and by the rate constants for water-ligand interchange in complex formation, $k_{34}$, with $\mathrm{SO}_{4}{ }^{2-} \cdot{ }^{[15,16]}$ Actually, there is an equilibrium between the 9- and 8-coordinated species with an easy dissociation or addition of a water molecules. This special situation explains the very short residence times of $\tau_{\mathrm{H}_{2} \mathrm{O}}$ $<20 \mathrm{~ns}$ for these highly charged cations when compared to other +3 ions. The only +2 lanthanide studied for water exchange dynamics is $\mathrm{Eu}^{2+}$, which is isoelectronic with $\mathrm{Gd}^{3+}{ }^{\left[{ }^{[43,44]}\right.}$ The water residence time of $\tau_{\mathrm{H}_{2} \mathrm{O}} \sim 0.2 \mathrm{~ns}$ measured on $\left[\mathrm{Eu}\left(\mathrm{H}_{2} \mathrm{O}\right)_{8}\right]^{2+}$ is the shortest ever directly measured.

\section{Conclusions}

The following general conclusions can be drawn on the variation of water residence times on monoatomic ion in aqueous solution.

- Water residence times on cations with closed shell electronic configuration (groups 1, 2, 3, 12,13) are mostly very short $\left(\tau_{\mathrm{H}_{2} \mathrm{O}}<10 \mathrm{~ns}\right)$. Exceptions are the small and highly charged ions $\mathrm{Be}^{2+}, \mathrm{Mg}^{2+}$ and $\mathrm{Al}^{3+}$. For these ions, $\tau_{\mathrm{H}_{2} \mathrm{O}}$ decreases with the ionic radius and with the positive charge (Fig. 6).

- Interactions between monoatomic halide anions and water are very weak and water residence times are shorter than $0.1 \mathrm{~ns}$. This is still an order of magnitude longer than translational motion of $\mathrm{H}_{2} \mathrm{O}$ molecules in pure water which is $\sim 3$ ps for translational diffusion.

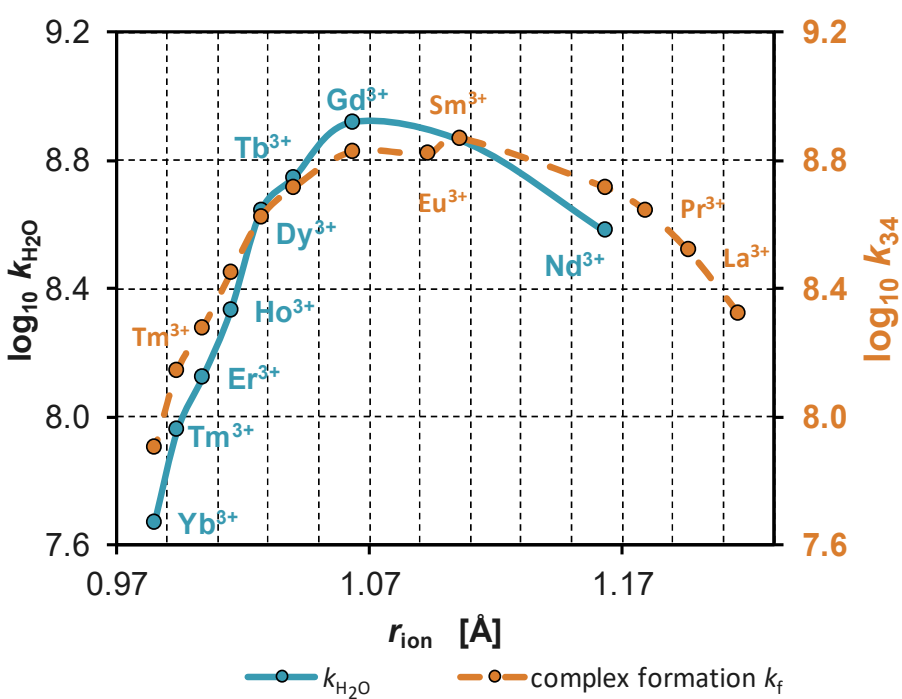

Fig. 5. Water exchange rate constants and rate constants for complex formation with $\mathrm{SO}_{4}^{2-[16]} k_{34}$ on lanthanide cations as a function of the ionic radius (Shannon). ${ }^{[25]}$

- Water residence times on d-block transition metal ions vary tremendously over nearly 19 orders of magnitude with $\tau_{\mathrm{H}_{2} \mathrm{O}}$ $\sim 10^{10} \mathrm{~s}$ for $\mathrm{Ir}^{3+}$ and $\tau_{\mathrm{H}_{2} \mathrm{O}} \sim 10^{-9} \mathrm{~s}$ for $\mathrm{Cu}^{2+}$. For these ions, the filling of the d-orbitals is of major importance. Ligand field stabilization can be very important as well as special effects like the Jahn-Teller distortion of the octahedral symmetry of the first coordination sphere.

- Water exchange on second and third row d-block transition metal ions is orders of magnitude slower when compared to first row transition metal ions. This is due to stronger ligand field stabilization energy on these ions, which is in turn due to the greater covalent character of the bonding in these complexes.

- On +3 lanthanide ions the absence of ligand field stabilization and the equilibrium between nine and eight coordination leads to very fast water exchange. The peculiar variation of $\tau_{\mathrm{H}_{2} \mathrm{O}}$ showing a maximum in the middle of the series is in contrast to the steady decrease of the ionic radii (Fig. 5). The shortest water residence time directly measured on $\left[\mathrm{Eu}\left(\mathrm{H}_{2} \mathrm{O}\right)_{8}\right]^{2+}$ is $0.2 \mathrm{~ns}$.

Because the chemistry of life takes place essentially in aqueous solution, water exchange on ions has important influence on biochemistry. The rate-determining step in most complex forma-

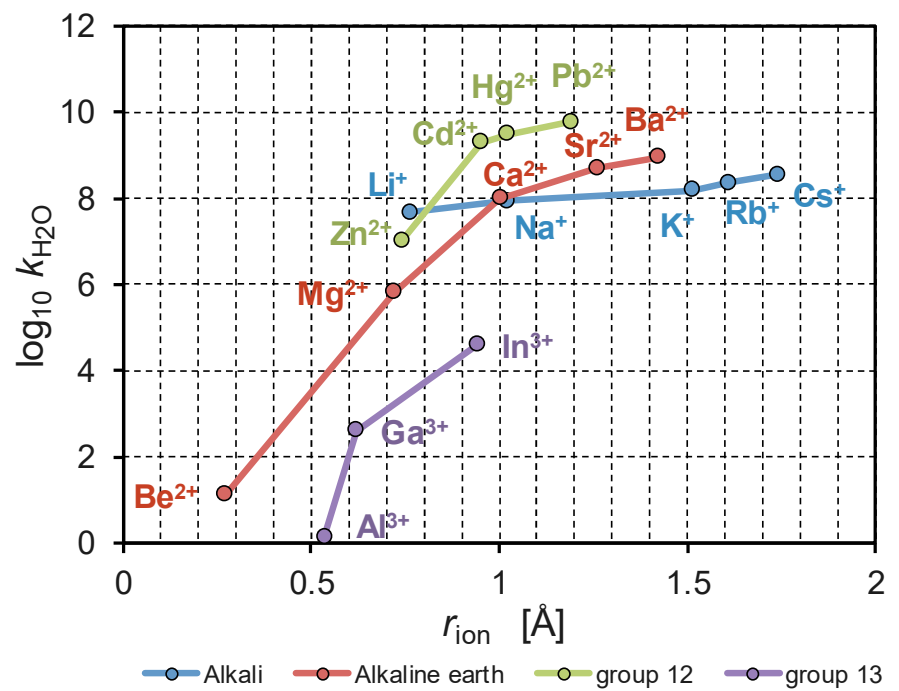

Fig. 6. Water exchange rate constants on closed shell cations as a function of the ionic radius (Shannon). ${ }^{[25]}$ 
tion reactions is the replacement of water from the first coordination shell.

\section{Acknowledgements}

The authors like to thank the Swiss National Science Foundation for supporting over many years their fundamental studies on solvent residence times and on solvent exchange mechanisms.

Received: February 6, 2019

[1] D. I. Mendeleev, J. Russ. Chem. Soc. 1869, 3, 25.

[2] D. I. Mendeleev, Z. Chem. 1869, 12, 405.

[3] S. G. Brush, Isis 1996, 87, 595, DOI: 10.1086/357649.

[4] P. Waage, C. M. Guldberg, Forh. Vidensk.-Selsk. Christ. 1864, 35.

[5] J. H. van't Hoff, E. Cohen, T. M. Ewan, 'Studies in Chemical Dynamics', Frederik Muller \& Co; Williams \& Norgate, Amsterdam, London, 1896.

[6] T. J. Swift, R. E. Connick, J. Chem. Phys. 1962, 37, 307, DOI: $10.1063 / 1.1701321$.

[7] M. Eigen, R. G. Wilkins, Adv. Chem. Ser. 1965, 49, 55, DOI: 10.1021/ba1965-0049.ch003.

[8] A. K. Soper, K. Weckström, Biophys. Chem. 2006, 124, 180, DOI: 10.1016/j. bpc.2006.04.009.

[9] C. H. Langford, H. B. Gray, 'Ligand Substitution Processes', W. A Benjamin, Inc., New York, 1965.

[10] W. Plumb, G. M. Harris, Inorg. Chem. 1964, 3, 542, DOI: 10.1021/ ic50014a021.

[11] F. C. Xu, H. R. Krouse, T. W. Swaddle, Inorg. Chem. 1985, 24, 267, DOI: 10.1021/ic00197a005.

[12] D. Hugi Cleary, L. Helm, A. E. Merbach, Helv. Chim. Acta 1985, 68, 545, DOI: $10.1002 /$ hlca.19850680302.

[13] L. Helm, G. M. Nicolle, A. E. Merbach, Adv. Inorg. Chem. 2005, 57, 327, DOI: $10.1016 / \mathrm{S} 0898-8838(05) 57007-7$.

[14] P. S. Salmon, Phys. B 1989, 156 \& 157, 129, DOI: 10.1016/09214526(89)90608-X.

[15] M. Eigen, Pure Appl. Chem. 1963, 6, 97, DOI: 10.1351/pac196306010097.

[16] D. P. Fay, D. Litchinsky, N. Purdie, J. Phys. Chem. 1969, 73, 544, DOI: 10.1021/j100723a012.

[17] C. Cossy, L. Helm, A. E. Merbach, Inorg. Chem. 1988, 27, 1973, DOI: 10.1021/ic00284a028.

[18] B. M. Rode, C. F. Schwenk, T. S. Hofer, B. R. Randolf, Coord. Chem. Rev. 2005, 249, 2993, DOI: 10.1016/j.ccr.2005.03.032.

[19] H. V. R. Annapureddy, L. X. Dang, J. Phys. Chem. B 2014, 118, 8917, DOI: 10.1021/jp502922c.

[20] I. Persson, Pure Appl. Chem. 2010, 82, 1901, DOI: 10.1351/PACCON-09-10-22.
[21] J. Mähler, I. Persson, Inorg. Chem. 2012, 51, 425, DOI: 10.1021/ic2018693.

[22] D. Spangberg, R. Rey, J. T. Hynes, K. Hermansson, J. Phys. Chem. B 2003 , 107, 4470, DOI: $10.1021 /$ jp027230f.

[23] P.-A. Pittet, G. Elbaze, L. Helm, A. E. Merbach, Inorg. Chem. 1990, 29, 1936, DOI: $10.1021 / \mathrm{ic} 00335 \mathrm{a} 034$.

[24] A. Bleuzen, P.-A. Pittet, L. Helm, A. E. Merbach, Magn. Reson. Chem. 1997, 35, 765, DOI: 10.1002/(SICI)1097-458X(199711)35:11<765::AIDOMR169>3.0.CO;2-F

[25] R. D. Shannon, C. T. Prewitt, Acta Crystallogr. B 1969, B25, 925, DOI: $10.1107 / \mathrm{S} 0567740869003220$

[26] L. Helm, A. E. Merbach, Chem. Rev. 2005, 105, 1923, DOI: 10.1021/ cr030726o.

[27] D. Hugi Cleary, L. Helm, A. E. Merbach, J. Am. Chem. Soc. 1987, 109, 4444, DOI: $10.1021 / \mathrm{ja} 00249 \mathrm{a} 003$.

[28] D. H. Powell, G. W. Neilson, J. E. Enderby, J. Phys. Condens. Matter 1993, $5,5723$.

[29] S. Koneshan, J. C. Rasaiah, R. M. Lynden-Bell, S. H. Lee, J. Phys. Chem. B 1998, 102, 4193, DOI: $10.1021 /$ jp980642x.

[30] H. V. R. Annapureddy, L. X. Dang, J. Phys. Chem. B 2014, 118, 7886, DOI: 10.1021/jp500402j.

[31] D. H. Powell, A. C. Barnes, J. E. Enderby, G. W. Neilson, P. S. Salmon, Faraday Discuss. Chem. Soc. 1988, 85, 137, DOI: 10.1039/DC9888500137.

[32] R. Mancinelli, A. Botti, F. Bruni, M. A. Ricci, A. K. Soper, J. Phys. Chem. B 2007, 111, 13570, DOI: 10.1021/jp075913v.

[33] A. Pasquarello, I. Petri, P. S. Salmon, O. Parisel, R. Car, É. Tóth, D. H. Powell, H. E. Fisher, L. Helm, A. E. Merbach, Science 2001, 291, 856, DOI: 10.1126/science.291.5505.856

[34] P. Frank, M. Benfatto, M. Qayyum, J. Chem. Phys. 2018, 148, 204302, DOI: $10.1063 / 1.5024693$

[35] A. E. Merbach, Pure Appl. Chem. 1987, 59, 161, DOI: 10.1351/ pac198759020161.

[36] D. H. Powell, L. Helm, A. E. Merbach, J. Chem. Phys. 1991, 95, 9258, DOI: $10.1063 / 1.461206$

[37] I. Rapaport, L. Helm, A. E. Merbach, P. Bernhard, A. Ludi, Inorg. Chem. 1988, 27, 873, DOI: $10.1021 / \mathrm{ic} 00278 \mathrm{a} 025$.

[38] D. R. Llewellyn, C. O'Connor (née Bishop), J. Chem. Soc. 1964, 545, DOI: 10.1039/JR9640000545.

[39] D. De Vito, E. Sidorenkova, F. P. Rotzinger, J. Weber, A. E. Merbach, Inorg. Chem. 2000, 39, 5547, DOI: 10.1021/ic0008262.

[40] C. Cossy, L. Helm, D. H. Powell, A. E. Merbach, New J. Chem. 1995, 19, 27 , DOI: $10.1039 / \mathrm{C} 8 \mathrm{NJ} 03372 \mathrm{~B}$.

[41] C. Cossy, L. Helm, A. E. Merbach, Inorg. Chem. 1989, 28, 2699, DOI: 10.1021/ic00313a003.

[42] S. Karimi, L. Helm, to be published

[43] P. Caravan, A. E. Merbach, Chem. Commun. 1997, 2147, DOI: 10.1039/ A705971J.

[44] P. Caravan, É. Tóth, A. Rockenbauer, A. E. Merbach, J. Am. Chem. Soc. 1999, 121, 10403, DOI: 10.1021/ja992264v. 